\title{
Analysis of the Educational Impact of M-Learning and Related Scientific Research
}

\author{
Javier Fombona ${ }^{1} \oplus$, María Angeles Pascual ${ }^{1} \oplus$ and Miguel Pérez Ferra ${ }^{2} \odot$ \\ ${ }^{1}$ Department Sciences of Education, University of Oviedo, Spain \\ ${ }^{2}$ Department of Pedagogy, University of Jaén, Spain
}

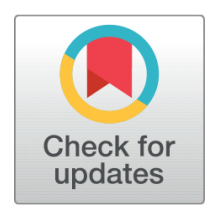

Received 2019-08-21

Revised 2019-09-06

Accepted 2020-02-10

Published 2020-07-15

\section{Corresponding Author}

Javier Fombona,

fombona@univi.es

Facultad de Formación del Profesorado y Educación, Aniceto Sela s.n Oviedo 33005 Spain

DOI https://doi.org/10.7821/ naer.2020.7.470

Pages: 167-180

Funding: Ministry of Economy and Competitiveness, Spain (Award: EDU2015-70491-R)

Distributed under

Creative Commons CC BY 4.0

Copyright: () The Author(s)

\section{ABSTRACT}

The deep penetration and global impact of mobile devices has led the scientific community to undertake a thorough analysis of the implications of this phenomenon. Researchers need to determine their true real effect and how they can best be used to manage information and build knowledge. This study has examined recent investigations on the subject of mobile learning and carried out a descriptive analysis of a sample of registers indexed on the Web of Science research platform in 2015-16. An exhaustive content analysis has revealed new areas where M-Learning is being implemented, especially in the teaching of foreign languages, the emergence of social interaction methodologies in Secondary Education, evolving forms of collaborative relationships, work with clearly defined student profiles and the use of virtual immersive and innovative spaces in Higher Education. This paper also emphasizes the presence of previously unknown, transcendent problems associated with M-learning, such as the collateral addiction effect, and its interference in the classroom. Finally, our study suggests that teachers could embrace these technological proposals and include them in their strategies. Indeed, it might be necessary to flip the process, so this research could be the start of the generation and design of innovative guidelines to manage these forms and content.

\section{Keywords ICT, KNOWLEDGE SOCIETY, LITERATURE REVIEW, MOBILE LEARNING, MULTIMEDIA MOBILE DEVICES}

\section{INTRODUCTION}

ICT literacy is not a static, universal and immutable construct, but is comprised of a series of skills in constant construction and evolution (Olivia-Dumitrina, Casanovas, \& Capdevila, 2019), so there are new highly changeable phenomena today that encompass widespread social repercussions, technological development and changes in personal interactions via mobile digital devices. This conjunction is both transversal and multidisciplinary, connecting marketing, communication and learning. These technologies have penetrated deep into all social layers and blurred geographical frontiers, and reach across all ages. This impact,

\section{OPEN ACCESS}


driven by powerful commercial interests, needs to be measured by the academic community to understand its true extent, its effect on the content of messages, and the new interactions between people, between people and institutions, and between people and machines. Recent UNESCO (2019) research has shown how the continuing development of Mobile Learning has led to scenarios involving Artificial Intelligence technologies, and hence the many ways governments and other organizations can leverage these new tools to accelerate the achievement of sustainable development.

Mobile Learning (M-Learning) is a kind of learning based on the methodologies of portable digital devices. The process of preparing teachers to use these strategies is underdeveloped, and many studies have explored this subject in a positive way. The main benefits include the potential to expand the classroom using the seamless affordances of these technologies, more personalised, collaborative learning both in and beyond the context of the classroom and the ability to situate learning in more authentic environments (Burden \& Kearney, 2016). The capacity of mobile devices to remain constantly connected generates a highly complex world of interaction and alters traditional communication. Users can produce content and convert any context into a new relation between the user and space and location. Weiser (1991) developed the concept of ubiquitous knowledge building, U-Learning, an environment with access to a range of digital services via equipment connected to the Internet whenever and wherever needed. All this transforms the architecture of knowledge in our society, generating new spaces that can be converted into sources of information far removed from the traditional educational framework. These scenarios provide an interesting field of analysis; this socio-cultural ecology where the autonomous relationship between the cultural context, physical framework and experimentation by users in their own environment are increasingly important. These users combine the key elements of their culture with the actions of these technologies which, for the first time, enable them, for example, to become the author-protagonists of messages that can have social repercussions.

The limitations of this research, in comparison to the scale of a complex and dynamic phenomenon such as M-Learning, oblige us to develop a more generalized view of the huge potential of these technologies in education, and to highlight possible advantages and the new methodologies and different pathways involved in knowledge building. However, these studies should not only focus on the students, but offer effective guidelines for teacher training; in this sense, UNESCO proffers important recommendations for policy-makers in order to achieve the unique benefits of this kind of learning (West \& Vosloo, 2013).

\section{MATERIAL AND METHODS}

\subsection{Objectives}

This analysis aims to describe the features of the recent scientific literature, and to identify the main research areas. The final objective is to provide a theoretical basis and systematize patterns of effective use of M-Learning in general. Subsequently, the results of this analysis, classified as rigorous, can suggest rules and strategies to implement these resources/methodologies at specific educational levels. 
In addition, the analysis will aid in identifying potential references for other professionals in the field, such as communicators, software engineers and experts, and areas for future research.

\subsection{Instrument and Procedures}

To achieve the objective of determining the potential of these advanced mobile digital devices, we examined the scientific output in this thematic area with a descriptive study that generates internally-related environments that can be correlated and subjected to contingency analysis in the form of two-dimensional tables based on the data sampled.

Bibliometric analysis strategies were applied to analyse the key themes of current scientific research. A transversal quantitative and qualitative survey of documents was carried out to find recent research work on the potential of advanced mobile digital devices for training and education. This involved compiling data from rigorous scientific databases such as Web of Science, and classifying them according to the subjects investigated and the results of implementation in each case. The quantitative aspect involved the selection of data based on counting frequencies and amounts per category; the qualitative part consisted of compiling bibliographic data, classifying them and analysing the content of abstracts to determine their main themes and results.

The work was based on an exhaustive analysis of Web of Science registers that enabled us to group and classify these registers and extract data values for specific fields. It was decided to search for key descriptive terms such as "M-Learning" and "Mobile Learning" in registers such as "Topic" and "Title". In the search, we considered documents on two levels of connection with the topic under investigation, namely those registers related to the topic and those in which key expressions form the nucleus of the work. Thus, in the first instance, the documents were related in various ways and at different degrees of depth, by determining a higher level of terms appearing in the title, in the abstract, or in the key words. In the second instance, and by avoiding repetitions, registers were detected that specifically included the words analysed; that is, the level of terms that appeared in their titles.

QDA Miner 3.24 text structuring software was used to process the content of the registers; this software enables the user to determine the set of representative characteristics in the texts. The software extracted and identified the concepts considered to be dimensions in the documents, and which constitute a taxonomic system that can be classified as a conceptual map of terms and descriptive expressions of the objectives formulated in this study. All the original files were converted into plain text using WinEdit 5.6 software; the data were cleaned, thus eliminating all internal format codes and characters, standardising orthography, and treating blocks, groups and subgroups.

\subsection{Study population and sample}

WoS houses scientific citations in more than 12,000 journals and 148,000 conference proceedings covering the sciences, social sciences, arts and humanities. The numbers of registers for the terms "M-Learning" and "Mobile learning" differed significantly (Table 1). 


\begin{tabular}{|c|c|c|}
\hline & "M-Learning" & \\
\hline Dimensions & $\begin{array}{l}\mathrm{N}^{\circ} \text { documents with "M-Learning" as title, in } \\
\text { abstract or key words }\end{array}$ & $\mathrm{N}^{\circ}$ documents with "M-Learning" in the title \\
\hline Total to 2016 & 1,365 & 461 \\
\hline \multirow[t]{3}{*}{$2015-2016$} & 428 & 123 \\
\hline & “Mobile Learning" & \\
\hline & $\begin{array}{l}\text { No documents with "Mobile Learning" as } \\
\text { title, in abstract or key words }\end{array}$ & No documents with "Mobile Learning" in the title \\
\hline Total to 2016 & 34,169 & 3,825 \\
\hline 2015-2016 & 9,099 & 1,145 \\
\hline
\end{tabular}

In terms of the descriptor population with terms related to Mobile Learning, the overall figure reached 35,535 registers. This obliged us to restrict the repository census and consider a scientifically convenient sampling of a specific space in time. Since these registers had a high dimension, we therefore opted for a sample from a particular time frame within the typology of this study, in which the units chosen for analysis complied with the criteria of the research objectives, in specific cases for the richness of the information selected (Avila, 1999). Therefore, in order to gather the most recent scientific output, the reference was the variable defined as "registers between 1 January 2015 and 31 December 2016". The sample was chosen from this particular period of time because prior references to technology risk becoming obsolete in both theory and practice. Furthermore, this time frame was notable for the considerable quantity of research produced in contrast to previous years.

This two-year time frame enabled us to work with a more manageable number of registers (Table 1). In WoS, the term "M-Learning" appears in 123 titles and in 428 document descriptors, while "Mobile learning" features in the title of 1,145 registers, and as a descriptor in 9,099 documents. It is important to note that the group total still retains a high dimension, which justifies the choice of registers in line with the model [M-Learning registers $\cup$ Mobile-Learning registers] $\cap$ [registers WoS $\cap$ registers 2015-2016]. However, given that the numbers were high, a random representative sample of 319 registers was selected within the sampling dates; for work with a $10 \%$ margin of error, a level of confidence of $95 \%$ and response distribution of $50 \%$. These dimensions were in line with the propositions of Chauhan, Bansal, and Ahuja (2015). Thus, this quantity was distributed across a sample of 12 documents with the term "M-Learning" as title, abstract and key words, and 4 appear in the title. For the term "Mobile-Learning", 270 registers were analysed with this term in the title, abstract and key words, and in 33 registers it appears in the title.

This research has several limitations; first the sample size may be small, since the volume of cases is not significant in qualitative studies. Second, M-learning does not have long-term stability since it is a very dynamic model. Nevertheless, the scientific characteristics of the sample and the findings of the study provide valuable insight into specific areas where it is being implemented. Although the results add an updated overview to the existing body of research, they do not align with more common meta-analyses approaches which generally 
identify a specific educational level or academic achievement, such as Po-Sheng's studies (2018).

\section{RESULTS}

\subsection{Qualitative data}

Table 2 presents the amounts and types of scientific works in which the terms appear as descriptors or as integral parts of the title of the document. The cases can be placed in various categories simultaneously, such that the overall total can exceed the amount $n$.

Table 2 Document typology 2015-2016

\begin{tabular}{|c|c|c|c|c|}
\hline \multirow[t]{2}{*}{ Type of document } & \multicolumn{2}{|c|}{$\begin{array}{l}\text { Documents with "Mobile Learning" as title, in } \\
\text { abstract or key words }\end{array}$} & \multicolumn{2}{|c|}{$\begin{array}{l}\text { Documents with "M-Learning" as title, in abstract or key } \\
\text { words }\end{array}$} \\
\hline & $\mathrm{n}=9,099$ & $\%$ & $\mathrm{n}=428$ & $\%$ \\
\hline Article & 5,203 & 57.18 & 171 & 39.95 \\
\hline Communication/presentation & 4,191 & 46.07 & 257 & 60.04 \\
\hline Review & 112 & 1.23 & 5 & 1.16 \\
\hline Abstract & 21 & 0.23 & 9 & 2.10 \\
\hline Book & 198 & 2.17 & 9 & 2.10 \\
\hline Other & 256 & 2.81 & & \\
\hline \multirow[t]{2}{*}{ Type of document } & \multicolumn{2}{|c|}{ "Mobile Learning" as title } & \multicolumn{2}{|c|}{ "M-Learning" as title } \\
\hline & $\mathrm{n}=1,145$ & $\%$ & $\mathrm{n}=123$ & $\%$ \\
\hline Article & 537 & 46.90 & 52 & 42.27 \\
\hline Communication/presentation & 581 & 50.74 & 73 & 59.34 \\
\hline Review & 20 & 1.74 & 1 & 0.81 \\
\hline Abstract & 11 & 0.96 & 1 & 0.81 \\
\hline Book & 114 & 9.95 & 2 & 1.16 \\
\hline Other & 12 & 1.04 & & \\
\hline
\end{tabular}

Table 3 presents the number of documents with the analysed terms distributed for main thematic areas. The registers can be simultaneously associated to various areas. Table 3 also shows the countries that have generated the highest number of documents.

\subsection{Quantitative data}

The content analysis of the investigations revealed a reiteration of a series of themes.

\subsubsection{Production related to conceptualization and typologies}

Firstly, a significant review of related scientific concepts was observed. A recurring element was the need to frame in terminological and conceptual terms the phenomenon derived from these technological developments, which appears as the advance of portable technology and a way to insert resources outside the education system into a virtual space. Students use these tools anytime, anywhere and create their own language in relation to their use of new documents, videos, multimedia and a mixed reality in digital environments. 
Table 3 Thematic areas of the documents and countries

\begin{tabular}{|c|c|c|}
\hline Thematic areas & $\begin{array}{l}\text { Documents with "M-Learning" as title, in abstract or key } \\
\text { words }\end{array}$ & Documents with "M-Learning" in the title \\
\hline Social Sciences & 182 & 56 \\
\hline Technology Sciences & 152 & 52 \\
\hline Computing and Engineering & 137 & 46 \\
\hline Physical Science & 11 & 4 \\
\hline Biomedicine & 21 & 10 \\
\hline Arts and Humanities & 15 & 2 \\
\hline \multicolumn{3}{|l|}{ Countries } \\
\hline China & 52 & 12 \\
\hline Spain & 43 & 15 \\
\hline Portugal & 23 & 2 \\
\hline Czech Republic & 22 & 3 \\
\hline England & 20 & 3 \\
\hline USA & 20 & 4 \\
\hline Brazil & 18 & 12 \\
\hline Taiwan & 16 & 3 \\
\hline Mexico & 15 & 7 \\
\hline Others & $\ldots$ & $\ldots$ \\
\hline Thematic areas & $\begin{array}{l}\text { Documents with "Mobile Learning" as title, in abstract or } \\
\text { key words }\end{array}$ & Documents with "Mobile Learning" in the title \\
\hline Social Sciences & 2,372 & 423 \\
\hline Technology Sciences & 4,405 & 468 \\
\hline Computing and Engineering & 4023 & 416 \\
\hline Physical Science & 1,047 & 53 \\
\hline Biomedicine & 916 & 87 \\
\hline Arts and Humanities & 203 & 42 \\
\hline \multicolumn{3}{|l|}{ Countries } \\
\hline USA & 1805 & 191 \\
\hline China & 1474 & 262 \\
\hline England & 1005 & 128 \\
\hline Taiwan & 384 & 88 \\
\hline Spain & 586 & 64 \\
\hline Germany & 530 & 55 \\
\hline Australia & 332 & 54 \\
\hline Malaysia & 211 & 52 \\
\hline India & 415 & 21 \\
\hline Canada & 375 & 41 \\
\hline Others & $\ldots$ & $\ldots$ \\
\hline
\end{tabular}


They become the authors of new narratives (Gimhyesuk, 2016). The appearance of new terminology derived from this process is observed, and this is a complex scenario which is difficult to categorize; as a result, authors such as Yousafzai, Chang, Gani, and Noor (2016) have presented a taxonomy of technical variables on the applications of these devices, and their educational capabilities. This taxonomy connects the technological heterogeneity, networks, the typology and characteristics of the content and users' expectations. Potkonjak et al. (2016) systematized these concepts linked to learning outside traditional settings, thus rendering it logical not to use the same terminology.

\subsubsection{Production related to new technologies and the potential of the visual narrative}

M-Learning is a new way of transmitting information and converting it into knowledge. It occurs in a dynamic of continuous change, which forces us to adapt to speedy innovations that universal users assume as consumers in the mobile digital device market. But research describes it not only as a change of tangible aspects such as ubiquitous access to information but as a shift in information management methodologies which goes beyond the use of an important technological component. The most radical modification is the passing of the written narrative to the iconic, given that the majority of interactions with these devices are audiovisual in nature (Pejoska, Bauters, Purma, \& Leinonen, 2016). All this means reassessing the styles and techniques of knowledge-building in this new scenario, with the emergence of models such as emoticons as unifying substitutions for text and emotions (Castro et al., 2016). Of particular interest is the study by Furió, Juan, Seguí, and Vivó (2015), which analysed the common uses of these devices by students, and observed that they always associated these devices with play, hence a greater disposition towards gaming activities.

\subsubsection{Production related to autonomy and collaboration}

Mobile devices change the procedures for accessing information with no space, time, generational, cultural or geopolitical restrictions. They move away from traditional sources and environments (Vázquez-Cano, Sevillano, \& Fombona, 2016).

So, the differentiation between individual and group work is being superseded by the complex interactions generated by these devices. Despite the fact that the smartphone is initially a tool of communication with a controlled and defined profile, the options for interpersonal relations on social networks, or between users and machines, are new pathways that are being explored by investigators (Hackett \& Proctor, 2016). Amara, Macedo, Bendella, and Santos (2016) have analysed these collaborative interactions and described a new scale of values that have emerged in the relationships between young people, drawing attention to the lack of systematic analyses of such groups within these interactive settings, because they are not created on the basis of clear methodological rules, and their new collaborative behaviours cannot be analysed using traditional value parameters. 


\subsubsection{Production related to immersive spaces.}

It is interesting to create a category for the new environments for the accessing and viewing of data. Potkonjak et al. (2016) summarized the state of this new technique related to laboratories and virtual worlds in the fields of science, technology and engineering, with special emphasis on robotics due to the maturity of this field within the development of technology. Thus, one variable of particular interest is the creation of simulated scenarios and laboratories. Reychav, Dunaway, and Kobayashi (2015) have classified these characteristics as access to new controlled sources, access to specific open content, and random access to diverse materials during daily activities, flowing within a given unplanned context. In this way, information and informal or spontaneous learning are mixed together. The interactions follow a similar pattern to the relationship between marketing and a product, in which behaviours develop in accordance with needs and the specific context of the experience.

The appearance of learning within Augmented Reality (AR) or full virtual reality contexts is the subject of in-depth research, with the analysis of behaviours and generated patterns that are unfamiliar to the academic world (Fombona, Coto, \& Caldevilla, 2015). Sakr, Jewitt, and Price (2016) explored the emotional involvement experienced with immersive devices, which opens new pathways to viewing information through a support that enriches reality with virtuality. Along similar lines, new materials are being developed such as the flow of electronic books or AR illustrations, and this trend is growing with the financial backing of official institutions in this field (Kopecky \& Szotkowski, 2016).

\subsubsection{Production related to particular levels and types of implementation}

There are a range of research results on these resources and their use in different areas. Rodrigo (2016) has analysed the didactic use of tablets and the methodologies used in primary and secondary education, suggesting that their use is influenced by the initial purpose of their acquisition, by pedagogical strategies established in the classroom, by the educational level of use and the range of related resources available to students. In primary schools, it seems that classroom dynamics have transformed as a result of widespread tablet use, with teachers tending to apply a traditional educational approach when it might be better to embrace the development of competences or focus more on the activities than the content. Castro et al. (2016) analysed M-Learning in Mathematics in secondary schools, emphasizing methodology related to social network use (Facebook and Twitter), and the objects of learning based on students' new styles and contexts. Moreover, fun and playing figure as part of the learning process and the use of tablets is prominent in promoting project-based teaching, this being yet another opportunity for teachers to rethink their traditional models (Suárez-Guerrero, Lloret-Catalá, \& Mengual-Andrés, 2016). University students and the Higher Education setting continue to be the users and scenarios most widely used for implementing the most advanced developments in technology, such as AR (Ferrer-Torregrosa, Torralba, Jimenez, García, \& Barcia, 2015). Another subject area used extensively for implementing these technologies is analysis of applications for learning 
English (Gimhyesuk, 2016). Likewise, Sung, Changb, and Liua (2016) analysed students' autonomous learning of English, and the positive impact on self-directed students' listening capacity. There are also other investigations on language learning through mobile devices, Mobile Assisted Language Learning (MALL) and their implications. Liu, Lu, and Lai (2016) reviewed the scientific literature and concluded that most research ratifies the efficacy and efficiency of these smart mobile devices, but differentiates the specific skills that they strengthen.

\subsubsection{Production related to new problems and challenges}

The use of technology increases students' tendency to learn more about their social and natural environment, and also enhances relations of an emotional nature (Huang, Chen, \& Chou, 2016). Closely linked is consideration of the problems related to the use of mobile devices and the regulatory system governing their use. Thus, in certain situations, these devices represent a disruption to the normal development of traditional tasks, and the usual peer relationships (Kaiiali, Ozkaya, Altun, Haddad, \& Alier, 2016). Students can suffer anxiety and addiction, because they have the feeling of missing messages. This modifies the level of attention, and the analysis correlates this to concentration and performance (Yang, Li, \& $\mathrm{Lu}, 2015)$. Legal aspects arise that have yet to be fully explored, in which new challenges emerge and full acceptance of virtual technology is questioned. On the institutional level, it seems that the penetration of the most advanced technologies is linked to infrastructure problems. There are significant impediments related to the management of space, the lack of necessary resources, and lack of well-equipped classrooms, in terms of such items as power supply and wireless connection (Alrasheedi, Capretz, \& Raza, 2016). Moreover, Burden and Hopkins (2016) identified main barriers as being related to capacity development, as opposed to less pressing problems, such as teachers' beliefs and attitudes.

\subsubsection{Production related to motivational and ergonomic factors}

The research reiterates the motivational factor generated by these developments driven by marketing techniques. It is futile to obviate the commercial impulse that underlies these instruments, boosting the market for ICT and pushing down the price of mobile devices that offer an ever-increasing choice of useful apps for a range of fields. The most common behaviours associated with mobile devices seem to be fun-oriented; leisure activities, music, as an element of self-gratification, communication with friends, and possibly for the access they provide to a wide variety of resources online. Lu and Liu (2015) stated that students appear to be happy and playful when they use these technologies. Karimi (2016) identified the individual characteristics that motivate students to make use of the wide range of apps on these devices, once again emphasising the new fun style inherent in each task, both in the formal and informal context in which the task takes place. Thus, directing the use of mobile devices towards developing specific competences should not only be about improving task performance but also about users' enjoyment of an experience that is fun and pleasurable. 
These materials are tools that are increasingly ergonomic. Navarro, Molina, Redondo, and Juarez-Ramirez (2016) have quantified the ease of use and usability of the user's interface. These conceptions are fundamental in their general application, and reinforce the strengths and weaknesses of their application in other settings, such as education, health or data management (Al-Emran, Elsherif, \& Shaalan, 2016). Nevertheless, researchers emphasise that some segments of the population continue to experience technical problems when handling these technologies, which fits with evidence found by Munoz-Cristobal et al. (2015).

\section{DISCUSSION AND CONCLUSIONS}

M-Learning generates new educational approaches and environments, based on the flexible interaction between users connected at a distance, anonymously or perfectly profiled; and between student-based communities; opening up communication between student and teacher at a distance; and also between student and machine. In this sense, the expansion of automatized virtual university campuses is the best example. This collaboration in new scenarios generates a range of new options capable of generating better educational performance. However, Drysdale, Graham, Spring, and Halverson (2013) insist on the advantage, among all these possibilities, of an intermediate situation that combines the use of machines with the physical presence of the teacher, B-Learning.

Research of the scientific output generated in 2015-16 highlighted the contribution of ephemeral documents related to technologies and the social sciences. The majority of registers were generated in a few countries (Table 3 ) and most of them are articles and presentations at conferences, while books accounted for less than $10 \%$ of production.

The qualitative analysis revealed the dominant themes in these WoS registers and, if compared to the content traditionally analysed and discussed around the state of the question, we observe how certain central topics continue to be investigated, such as the typological conceptualization and classification of the thematic area, the analysis of autonomous and collaborative uses generated by those instruments, the motivational and fun factors, the power of the visual narrative, and space-time delocalization. In this sense, the research supports the results of Kearney, Burden, and Rai (2015), highlighting the appearance of new places that can be sources of information and knowledge. These new places emphasize the uses of immersive scenarios, such as Augmented Reality in which users can situate themselves within digital environments like virtual laboratories or experience situations determined by their financial, social or geographic profile. As such, there is an opportunity to present the specific virtual scenarios that provide students with new immersive experiences in three-dimensional books. Researchers suggest that this new virtual world is no longer an experience in Higher Education but reaches Early Childhood Classrooms (Roig-Vila, Lorenzo-Lledó, \& Mengual-Andrés, 2019). Being affordable allows these tools to penetrate all areas, perhaps for the first time at the initial educational level (Pérez et al., 2019).

It is important to note the efficacy of marketing that drives the extensive use of these devices. The edu-communication conjunction with market strategies means personalized 
interaction that is measured to each user's needs. The analysis of the registers revealed studies of young people's online actions, configuring big data, where each student has a specific profile to be shaped, their needs attended to, and be sold specific goods and services. In this sense, the students with a low profile of knowledge are the ones with the lowest number of positive aspects and the least interest in training with these technologies (SalcinesTalledo, González-Fernández, \& Briones, 2020). Simultaneously, new problems have been detected but under-investigated so far, such as addiction, constant need for gratification, fear of being disconnected from online interactions, and disruption in normal classroom functioning. Chang, Chien, Yu, Lin, and Chen (2016) found a positive correlation between the perceptions of innovative environments and creative performance, but students see these instruments as a gateway to exploration, even to access documents previously banned, downloading and using non-recommended software.

In any case, it is interesting for the academic community to formulate proposals to society, industry and the authorities whose responsibility it is to regulate the actions undertaken with these instruments; for example, their non-disruptive use by students within the educational framework. It is deemed necessary for researchers to describe the objective features of these computer applications, for instance quantifying their real efficacy in education, since the only characteristics currently provided amount to guidance derived from the PEGI (Pan European Game Information) for the recommended age level for users. Such information on the usefulness of the available technology could help clarify the competences to be developed in the use of these tools, and how they contribute to the building of knowledge.

Researchers normally take as a reference point users' patterns of behaviour with their mobile devices in their normal everyday lives. Such patterns become hidden within the intimacy sphere and this poses a challenge to proposing an educational theory. In this sense, one particular need detected is the configuration of a consolidated theoretical corpus, differentiated by level and educational area in order to help teachers in their daily tasks with these new digital technologies, beyond commercial interests. M-Learning that is quantitatively strengthened by the worldwide penetration of these devices does not just have a qualitative dimension but also imposes new frameworks of interaction and learning dynamics. It seems logical that teachers make the most of these resources and methodologies, and that their training includes the development of related competences; for instance, to make their communication more personalised and attractive, and able to counter underachievement at school. This is a question of focusing on classic socio-educational problems not only through the prism of traditional variables and categories but by incorporating successful practices derived from the phenomenon of mobile devices.

\section{ACKNOWLEDGEMENTS}

Funded by: Ministry of Economy and Competitiveness, Spain

Funder Identifier: http://dx.doi.org/10.13039/501100003329

Award: EDU2015-70491-R 


\section{REFERENCES}

Al-Emran, M., Elsherif, H. M., \& Shaalan, K. (2016). Investigating attitudes towards the use of mobile learning in higher education. Computers in Human Behavior, 56, 93-102. https:// doi.org/10.1016/j.chb.2015.11.033

Alrasheedi, M., Capretz, L. F., \& Raza, A. (2016). Management's Perspective on Critical Success Factors Affecting Mobile Learning in Higher Education Institutions-An Empirical Study. Journal of Educational Computing Research, 54(2), 253-274. https://doi.org/10.1177/ 0735633115620387

Amara, S., Macedo, J., Bendella, F., \& Santos, A. (2016). Group formation in mobile computer supported collaborative learning contexts: A systematic lit-erature review. Educational Technology \& Society, 19(2), 258-273.

Ávila, H. (1999). Introduction to Research Methodology. México: Technological Institute Cuauhtémoc.

Burden, K., \& Hopkins, P. (2016). Barriers and Challenges Facing Pre-Service Teachers use of Mobile Technologies for Teaching and Learning. International Journal of Mobile and Blended Learning, 8(2), 1-20. https://doi.org/10.4018/ijmbl.2016040101

Burden, K., \& Kearney, M. (2016). Conceptualising authentic Mobile Learning. In D. Churchill, J. Lu, T. K. Chiu, \& B. Fox (Eds.), Mobile Learning design: Theories and application (pp. 27-42). Singapore: Springer. https://doi.org/10.1007/978-981-10-0027-0_2

Castro, G. G., Dominguez, E. L., Velazquez, Y. H., Matla, M. Y. R., Toledo, C. B. E., \& Hernandez, S. E. P. (2016). MobiLearn: Context-Aware Mobile Learning System. IEEE Latin America Transactions, 14(2), 958-964. https://doi.org/10.1109/tla.2016.7437246

Chang, Y., Chien, Y. H., Yu, K., Lin, H., \& Chen, M. (2016). Students' innovative environmental perceptions and creative performances in cloud-based M-learning. Computers in Human Behavior, 63, 988-994. https://doi.org/10.1016/j.chb.2016.06.032

Chauhan, V. S., Bansal, R., \& Ahuja, M. (2015). Comparison of efficacy and tolerance of shortduration open-ended ureteral catheter drainage and tamsulosin administration to indwelling double J stents following ureteroscopic removal of stones. Hong Kong Medical Journal, 21(2), 124-130. https://doi.org/10.12809/hkmj144292

Chiu, P.-S., Pu, Y.-H., Kao, C.-C., Wu, T.-T., \& Huang, Y.-M. (2018). An authentic learning based evaluation method for mobile learning in Higher Education. Innovations in Education and Teaching International, 55(3), 336-347. https://doi.org/10.1080/14703297.2017.1417147

Drysdale, J. S., Graham, C. R., Spring, K. J., \& Halverson, L. R. (2013). An analysis of research trends in dissertations and theses studying blended learning. The Internet and Higher Education, 17, 90-100. https://doi.org/10.1016/j.iheduc.2012.11.003

Ferrer-Torregrosa, J., Torralba, J., Jimenez, M. A., García, S., \& Barcia, J. M. (2015). ARBOOK: Development and Assessment of a Tool Based on Augmented Reality for Anatomy. Journal of Science Education and Technology, 24(1), 119-124. https://doi.org/10.1007/s10956-014-9526 $-4$

Fombona, J., Coto, V., \& Caldevilla, D. (2015). Mobile Augmented Reality interaction: an approach to the phenomenon. Informação \& Sociedade: Estu-dos, 25(3), 117-129.

Furió, D., Juan, M. C., Seguí, I., \& Vivó, R. (2015). Mobile learning vs. traditional classroom lessons: a comparative study. Journal of Computer Assisted Learning, 31(3), 189-201. https://doi.org/ 10.1111/jcal.12071

Gimhyesuk. (2016). A study on mobile application design for English vocabulary learning. The Journal of Linguistics Science, 78, 67-99. https://doi.org/10.21296/j1s.2016.09.78.67

Hackett, M., \& Proctor, M. (2016). Three-Dimensional Display Technologies for Anatomical Edu- 
cation: A Literature Review. Journal of Science Education and Technology, 25(4), 641-654. https://doi.org/10.1007/s10956-016-9619-3

Huang, T., Chen, C., \& Chou, Y. (2016). Animating eco-education: To see, feel, and discover in an augmented reality-based experiential learning environment. Computers \& Education, 96, 72-82. https://doi.org/10.1016/j.compedu.2016.02.008

Kaiiali, M., Ozkaya, A., Altun, H., Haddad, H., \& Alier, M. (2016). Designing a Secure Exam Management System (SEMS) for M-Learning Environments. IEEE Transactions on Learning Technologies, 9(3), 258-271. https://doi.org/10.1109/tlt.2016.2524570

Karimi, S. (2016). Do learners' characteristics matter? An exploration of mobile-learning adoption in self-directed learning. Computers in Human Behavior, 63, 769-776. https://doi.org/10 .1016/j.chb.2016.06.014

Kearney, M., Burden, K., \& Rai, T. (2015). Investigating teachers' adoption of signature mobile pedagogies. Computers \& Education, 80, 48-57. https://doi.org/10.1016/j.compedu.2014.08 .009

Kopecky, K., \& Szotkowski, R. (2016). Use of mobile touch devices as part of lifelong learning with specific focus on tablets. ICLEL 2015 Conference on Lifelong Learning and Leadership for All (pp. 221-225).

Liu, G., Lu, H., \& Lai, C. (2016). Towards the construction of a field: The developments and implications of Mobile Assisted Language Learning (MALL). Digital Scholarship in the Humanities, 31(1), 164-180. https://doi.org/10.1093/1lc/fqu070

Lu, S., \& Liu, Y. (2015). Integrating Augmented Reality technology to enhance children's learning in marine education. Environmental Education Research, 21(4), 525-541. https://doi.org/ 10.1080/13504622.2014.911247

Munoz-Cristobal, J. A., Jorrin-Abellan, I. M., Asensio-Perez, J. I., Martinez-Mones, A., Prieto, L. P., \& Dimitriadis, Y. (2015). Supporting Teacher Orchestration in Ubiquitous Learning Environments: A Study in Primary Education. IEEE Transactions on Learning Technologies, 8(1), 83-97. https://doi.org/10.1109/tlt.2014.2370634

Navarro, C. X., Molina, A., Redondo, M. A., \& Juarez-Ramirez, R. (2016). Framework to Evaluate M-Learning Systems: A Technological and Pedagogical Approach. RITA-IEEE, 11(1), 33-40. https://doi.org/10.1109/rita.2016.2518459

Olivia-Dumitrina, N., Casanovas, M., \& Capdevila, Y. (2019). Academic Writing and the Internet: Cyber-Plagiarism amongst University Students. Journal of New Approaches in Educational Research, 8(2), 112-112. https://doi.org/10.7821/naer.2019.7.407

Pejoska, J., Bauters, M., Purma, J., \& Leinonen, T. (2016). Social augmented reality: Enhancing context-dependent communication and informal learning at work. British Journal of Educational Technology, 47(3), 474-483. https://doi.org/10.1111/bjet.12442

Pérez, A., Pérez-Ferra, M., Fombona, J., González, J., López, R., Sierra, B., \& Neira, M. (2019). Evaluación y desarrollo de las competencias comunicativa y digital en estudiantes del grado de maestro. Barcelona: Graó.

Potkonjak, V., Gardner, M., Callaghan, V., Mattila, P., Guetl, C., Petrović, V. M., \& Jovanović, K. (2016). Virtual laboratories for education in science, technology, and engineering: A review. Computers \& Education, 95, 309-327. https://doi.org/10.1016/j.compedu.2016.02.002

Reychav, I., Dunaway, M., \& Kobayashi, M. (2015). Understanding mobile technology-fit behaviors outside the classroom. Computers \& Education, 87, 142-150. https://doi.org/10.1016/ j.compedu.2015.04.005

Rodrigo, L. (2016). The didactic and methodological use of tablets in classrooms of primary and secondary education in Catalonia. Pixel-Bit, 48, 9-25. https://doi.org/10.12795/pixelbit.2016 .148 .01 
Roig-Vila, R., Lorenzo-Lledó, A., \& Mengual-Andrés, S. (2019). Utilidad percibida de la realidad aumentada como recurso didáctico en Edu-cación Infantil. Campus virtuales, 8(1), 19-35.

Sakr, M., Jewitt, C., \& Price, S. (2016). Mobile Experiences of Historical Place: A Multimodal Analysis of Emotional Engagement. Journal of the Learning Sciences, 25(1), 51-92. https:// doi.org/10.1080/10508406.2015.1115761

Salcines-Talledo, I., González-Fernández, N., \& Briones, E. (2020). The Smartphone as a Pedagogic Tool. Student Profiles as related to its Use and Knowledge. Journal of New Approaches in Educational Research, 9(1), 91-109. https://doi.org/10.7821/naer.2020.1.454

Suárez-Guerrero, C., Lloret-Catalá, C., \& Mengual-Andrés, S. (2016). Teachers' perceptions of the digital transformation of the classroom through the use of tablets: A study in spain. Comunicar, 49, 81-89. https://doi.org/10.3916/C49-2016-08

Sung, Y., Changb, K., \& Liua, T. (2016). The effect of flow experience on English listening and self-directed learning abilities through a listening activity using a smartphone application. Multimedia-Assisted Language Learning, 19(3), 158-177. https://doi.org/10.15702/mall.2016 .19.3.158

UNESCO. (2019). Artificial intelligence in education, compendium of promising initiatives: Mobile Learning Week. Paris: Author.

Vázquez-Cano, E., Sevillano, M., \& Fombona, J. (2016). Analysis of the educa-tional and social use of digital devices in the pan-Hispanic university con-text. Revista De Investigación Educativa, 34(2), 453-469. https://doi.org/10.6018/rie.34.2.224691

Weiser, M. (1991). The Computer for the 21st Century. Scientific American, 265(3), 94-104. https:// doi.org/10.1038/scientificamerican0991-94

West, M., \& Vosloo, S. (2013). The policy guidelines for mobile learning. United Nations Educational, Scientific and Cultural Organization. Paris: UNESCO.

Yang, X., Li, X., \& Lu, T. (2015). Using mobile phones in college classroom settings: Effects of presentation mode and interest on concentration and achievement. Computers \& Education, 88, 292-302. https://doi.org/10.1016/j.compedu.2015.06.007

Yousafzai, A., Chang, V., Gani, A., \& Noor, R. M. (2016). Multimedia augmented m-learning: Issues, trends and open challenges. International Journal of Information Management, 36(5), 784-792. https://doi.org/10.1016/j.ijinfomgt.2016.05.010 